\title{
Current Status of Adipose-Derived Mesenchymal Stem Cells in Cartilage Repair
}

Arianna L Gianakos ${ }^{1,2^{\star}}$ and John G Kennedy ${ }^{2}$

${ }^{1}$ Jersey City Medical Center, 355 Grand Street, Jersey City, USA

${ }^{2}$ Hospital for Special Surgery, 523 East 72nd Street, New York, USA

*Corresponding author: Arianna L Gianakos, Hospital for Special Surgery, New York, NY 10021, USA, Tel: (908)-797-3497; Fax: 4832 2699833; E-mail: algianakos@gmail.com

Received date: August 16, 2016; Accepted date: August 27, 2016; Published date: August 30, 2016

Copyright: (c) 2016 Gianakos AL, et al. This is an open-access article distributed under the terms of the Creative Commons Attribution License, which permits unrestricted use, distribution, and reproduction in any medium, provided the original author and source are credited.

\begin{abstract}
Mesenchymal stem cells (MSCs) have gained increased attention in the treatment of injury-related cartilage damage. Most of the literature has focused on the use of bone marrow MSCs for chondrogensis; however its clinical use has presented consequences of donor site morbidity and pain as well as low cell number during harvest. Adipose tissue offers an abundant source of mesenchymal stem cells (MSCs), showing promise for the treatment of cartilaginous injuries. Numerous studies have focused on the safety and efficacy of adipose-derived mesenchymal stem cells (ADSC) in the form of the stromal vascular fraction (SVF), supporting its use in future clinical applications. While reports of ADSC potential for cartilage repair have been encouraging, the lack of standardization among studies, as well as the confusing terminology describing the different forms of ADSC presents cause for deeper investigation of those studies reporting clinical success. Overall, ADSCs show significant potential as an alternative and/or adjunctive treatment of cartilaginous injuries.
\end{abstract}

Keywords: Adipose-derived mesenchymal stem cell; Stromal vascular fraction; Cartilage

\section{Short Communication}

Cartilage injury has become a major cause of disability, and the limited potential for self-regeneration and repair of cartilaginous tissue makes treatment challenging. The poor regenerative capability of chondral tissue has been attributed to the avascular environment the chondrocytes reside in, preventing the access and survival of stem cells to the injured area for repair [1]. Techniques to treat cartilage disorders range from invasive graft procedures including osteochondral autograft transfer, abrasion arthroplasty, microfracture and subchondral drilling to cell based therapies such as autologous chondrocyte implantation and mesenchymal stem cell therapy. The use of autologous mesenchymal stem cells (MSCs) as part of a regenerative based approach in the treatment of cartilaginous injuries has received increased attention as the long term outcomes of bone marrow stimulation and other reparative therapies have been less encouraging [2].

MSCs have the potential to differentiate into several lines such as osteoblasts, chondrocytes, myoblasts or adipocytes with the capability of self-renewal, high plasticity and immunosuppressive and antiinflammatory action $[3,4]$. MSCs can be obtained from a variety of human sources including periosteum, muscle, synovial membrane, and adipose tissue. Although numerous studies have reported the benefits in treating cartilage injuries with MSCs, the mechanism of action of the regenerative effects of MSCs still remains unclear. There is some evidence to suggest that MSCs function through secretory cytokine action on injured and surrounding tissue, while other evidence suggests that MSCs survive implantation and restore native tissue direction with their own cellular machinery differentiating into chondrocytes [1]. Most of the recent literature has focused on the clinical use of bone marrow mesenchymal stem cells (BMSCs) for chondrogenesis. Donor site morbidity, pain and low cell number upon harvest has led to investigation of other sources.

Adipose derived mesenchymal stem cells (ADSCs) have become an attractive alternative to the well-researched bone marrow mesenchymal stem cell (BMSCs). Adipose tissue is rich in capillary beds, thereby harboring one of the largest depots of MSCs [1]. Increased interest in ADSCs reside in their abundance, ease of harvest, rapid expansion and high proliferation potential, as well as their ability to better maintain their phenotype with respect to BMSCs $[4,5]$. Preparation of ADSCs is also easier and less expensive than BMSCs, and the cultured lineage has shown a similar function to BMSCs in multi-lineage differentiation [6]. ASCs have an additional advantage in that they hold and maintain greater chondrogenic potential for over 15 culture expansions [7].

Much of the recent literature has focused on the use of ADSCs in the form of stromal vascular fraction (SVF). The SVF contains different proportions of ADSCs, pericytes, vascular adventitia cells, fibroblasts, preadipocytes, monocytes, macrophages and red blood cells [8]. ADSCs, however, may only represent up to $10 \%$ of the SVF [9]. It has been suggested that SVF can be applied as a one-step surgical procedure for cartilage regeneration [10]. While reports of ADSC potential for cartilage repair have been encouraging, there is some cause for deeper investigation of those studies reporting clinical success. The first concern is the nomenclature used. Stem cell therapies should have a significant portion of the therapeutic delivery consisting of stem cells. At best, the current method of preparation of ADSCs has just $10 \%$ stem cells fraction as part of the therapeutic dosing [11]. These methods currently produce a stromal vascular fraction. Therefore, the stem cells contained in this biologic milieu may have little if any impact on chondrogenesis when compared to the pericytyes, fibroblasts and other growth factors contained in the SVF. This is not to implicate the current research on ADSCs as spurious, but rather it underscores the current vague and confusing nature of nomenclature in stem cell therapies. Another limitation in the recent 
Page 2 of 2

literature is the lack of standardization of the type of ADSC derived when evaluating its benefits chondrogensisis. It is known that infrapatellar fat pad (IFP) can give rise to cells with significant chondrogenic potential by comparison to those derived from perigluteal region or BMSCs [12]. Future investigations will need to characterize not only the area that the graft was derived from, but will also need to define clearly the preparation method used. Currently, collagenase is not approved by many regulatory boards for use in ADSC preparation for human use.

Despite the apparent confusion in the existing literature there is no doubt that ADSCs with or without the SVF have a role in chondrogenesis. There have been numerous reports demonstrating the ability of adipose tissue-derived stromal cells to produce characteristic cartilage matrix molecules in both in vitro and in vivo models suggesting the potential of these cells in cartilage tissue engineering [13]. In addition, there have been several studies that have provided evidence of cartilage regeneration in osteoarthritis [14]. There have also been several clinical trials which have reported improved patient satisfaction and improved VAS scores with the use of ADSCs in the treatment of injury-related cartilage damage $[15,16]$. ADSCs have also been shown to be a mediator of tissue regeneration through secretion of multiple growth factors including fibroblast growth factor, vascular endothelial growth factor, insulin-like growth factor-1, hepatocyte growth factor and transforming growth factor $[17,18]$. In addition to growth factor secretion, ADSCs are also responsive to growth factors, and thereby can regenerate tissue more effectively [17]. Literature has demonstrated that the stem cell may not actually be involved in direct cartilage repair, but rather may simply act as a signal for other growth factors to promote and initial cartilage production.

Overall, there has been evidence in the literature demonstrating the chondrogenic potential, as well as the symptomatic improvement in patients with cartilaginous injury when utilizing ADSCs in the form of SVF. It is anticipated that future studies will report on safety testing that can be replicated when using SVF and ADSC ultimately accelerating the clinical translation process [19]. Correct nomenclature is necessary in order to provide meaningful analysis of the currently published literature. Standardization of both the preparation methods, as well as the characterization of the derived ADSC is critical when determining the effectiveness of ADSCs with or without SVF. Overall ADSCs show significant promise as part of a regenerative based approach in the treatment of cartilaginous injuries, as well as offer a practical modality of obtaining MSCs for clinical application.

\section{References}

1. Kasir R, Vernekar VN, Laurencin CT (2015) Regenerative engineering of cartilage using adipose-derived stem cells. Regenerative Engineering and Translational Medicine 1: 42-49.

2. Smyth NA, Murawski CD, Haleem AM, Hannon CP, Savage-Elliott I, et al. (2012) Establishing proof of concept: Platelet-rich plasma and bone marrow aspirate concentrate may improve cartilage repair following surgical treatment for osteochondral lesions of the talus. World J Orthop 3: 101-108.

3. DiMarino AM, Caplan AI, Bonfield TL (2013) Mesenchymal stem cells in tissue repair. Frontiers in Immunology 4: 201.

4. Perdisa F, Gostypska N, Roffi A, Filardo G, Marcacci M, et al. (2015) Stem cells in articular cartilage regeneration. Stem Cells International 2015 11: 42.

5. Strioga M, Viswanathan S, Darinskas A, Slaby O, Michalek J (2012) Same or not the same? comparison of adipose tissue-derived versus bone marrow-derived mesenchymal stem and stromal cells. Stem Cells and Development 21: 2724-2752.

6. Zuk PA, Zhu M, Ashjian P, De Ugarte DA, Huang JI, et al. (2002) Human adipose tissue is a source of multipotent stem cells. Mol Biol Cell 13:4279-4295.

7. Huang JI, Zuk PA, Jones NF, Zhu M, Lorenz HP, et al. (2004) Chondrogenic potential of multipotential cells from human adipose tissue. Plast Reconstr Surg 113: 585-594.

8. Horwitz EM, Le Blanc K, Dominici M, Mueller I, Slaper-Cortenbach I, et al. (2005) International Society for Cellular Therapy. Clarification of the nomenclature for MSC: The International Society for Cellular Therapy position statement. Cytotherapy 7: 393-395.

9. Yoshimura K, Shigeura T, Matsumoto D, Sato T, Takaki Y, et al. (2006) Characterization of freshly isolated and cultured cells derived from the fatty and fluid portions of liposuction aspirates. Journal of Cellular Physiology 1: 64-76.

10. Jang Y, Koh YG, Choi YJ, Kim SH, Yoon DS, et al. (2015) Characterization of adipose tissue-derived stromal vascular fraction for clinical application to cartilage regeneration. In Vitro Cell Dev Biol Anim. 51: 142-150.

11. Baer PC, Geiger H (2012) Adipose-derived mesenchymal stromal/stem cells: Tissue localization, characterization and heterogeneity. Stem Cells International 2012: 11 .

12. Hindle P, Khan N, Biant L, Peault B (2016) The Infrapatellar fat pad as a source of perivascular stem cells with increased chondrogenic potential for regenerative medicine. Stem Cells Trans Med. [Epub ahead of print].

13. Erickson GR, Gimble JM, Franklin DM, Rice HE, Awad H, et al. (2002) Chondrogenic potential of adipose tissue-derived stromal cells in vitro and in vivo. Biochem Biophys Res Commun 290: 763-769.

14. Koh YG, Choi YJ, Kwon SK, Kim YS, Yeo JE (2015) Clinical results and second-look arthroscopic findings after treatment with adipose-derived stem cells for knee osteoarthritis. Knee Surg Sports Traumatol Arthrosc 23: 1308-1316.

15. Kim YS, Choi YJ, Koh YG (2015) Mesenchymal stem cell implantation in knee osteoarthritis: An assessment of the factors influencing clinical outcomes. Am J Sports Med 43: 2293-2301.

16. Koh YG, Choi YJ (2012) Infrapatellar fat pad-derived mesenchymal stem cell therapy for knee osteoarthritis. Knee19: 902-907.

17. Tsuji W, Rubin JP, Marra KC (2014) Adipose-derived stem cells: Implications in tissue regeneration. World J Stem Cells 6: 312-321.

18. Salgado AJ, Reis RL, Sousa NJ, Gimble JM (2010) Adipose tissue derived stem cells secretome: Soluble factors and their roles in regenerative medicine. Curr Stem Cell Res Ther 5:103-110.

19. Gimble JM, Bunnell BA, Chiu ES, Guilak F (2011) Concise review: Adipose-derived stromal vascular fraction cells and stem cells: Let's not get lost in translation. Stem Cells Translational and Clinical Research 29: 749-754. 